\title{
Luminescent Characteristic of Organic Compound-Containing Inorganic Crystal at Room Temperature
}

\author{
Norihito Doki*, Masaaki Yokota \\ Department of Chemistry and Bioengineering, Faculty of Engineering, Iwate University, Morioka, Japan \\ Email: ${ }^{*}$ doki@iwate-u.ac.jp
}

Received 29 July 2015; accepted 7 October 2015; published 12 October 2015

Copyright (C) 2015 by authors and Scientific Research Publishing Inc.

This work is licensed under the Creative Commons Attribution International License (CC BY). http://creativecommons.org/licenses/by/4.0/ (c) () Open Access

\begin{abstract}
The luminescent functional crystal was produced by the organic guest molecules conformation control in the inorganic host crystal matrix. Inorganic host-organic guest crystals were successfully prepared and luminescence spectra were investigated. These crystals had a phosphorescent property in room temperature by $254 \mathrm{~nm}$ UV irradiation. In this system, the potassium sulfate host matrix was effectively inhibited the molecular vibration of organic guest molecules by interaction between $\mathrm{K}+$ and $\pi$-electrons. In addition, control of the luminescence wavelength (both fluorescence and phosphorescence) was achieved by controlling the structure of organic molecules which were taken in anorganic compound-containing inorganic crystal. Specifically, theorganic compound-containing inorganic crystals with 2 -aminobenzenesulfonic acid and 2-naptylamine-1-sulfonic acid as a guest had a phosphorescence band of $455 \mathrm{~nm}$ and $510 \mathrm{~nm}$, respectively.
\end{abstract}

\section{Keywords}

Phosphorescence, Potassium Sulfate, 2-Aminobenzenesulfonic Acid

\section{Introduction}

White organic light-emitting diodes are of current interest from practical points of view due to their potential applications in next generation full-color flat-panel displays and solid-state lighting sources [1] [2]. Recently, a series of studies revealed that high efficiency organic light-emitting diodes could be fabricated by employing phosphorescent iridium complexes [3]-[6]. In general, organic light-emitting diodes is composed by the combination of three colors (blue, green and red) or two colors (blue and orange). Till now, many high efficient green

*Corresponding author.

How to cite this paper: Doki, N. and Yokota, M. (2015) Luminescent Characteristic of Organic Compound-Containing Inorganic Crystal at Room Temperature. Advances in Chemical Engineering and Science, 5, 441-446. 
and red emitters have been developed, but blue emitters with comparable low efficient. Thus, the development of the efficient and stable blue color component is hoped for [7]-[9].

In this paper, we report a very simple phosphorescent emitter based on inorganic-organic crystal systems. And we have examined the control of emission wavelength by adjustment of structure of organic guest components.

\section{Experimental Section}

To crystallize the organic compound-containing inorganic crystals, the solution was prepared by dissolving solute (inorganic and organic materials) in water solvent. In this crystallization, we tried three combinations: 1) $\mathrm{K}_{2} \mathrm{SO}_{4}+\mathrm{ABSA}$ (2-aminobenzenesulfonic acid), 2) $\mathrm{K}_{2} \mathrm{SO}_{4}+\mathrm{NS}$ (2-naptylamine-1-sulfonic acid), 3) $\mathrm{Rb}_{2} \mathrm{SO}_{4}+$ ABSA [10]. Before crystallization, we examined the optimum ratio of inorganic and organic components. First, we dissolves $\mathrm{K}_{2} \mathrm{SO}_{4}$ or $\mathrm{Rb}_{2} \mathrm{SO}_{4}$ (16.23 g and $30.00 \mathrm{~g}$, respectively.) in $60^{\circ} \mathrm{C}$ water solution by using stirrer for 3 h. Then, organic materials were introduced in solution where the inorganic matter had dissolved. Finally, the codissolved water was cooled from $60^{\circ} \mathrm{C}$ to $10^{\circ} \mathrm{C}$ by constant cooling ratio $\left(0.5^{\circ} \mathrm{C} /\right.$ hour $)$ for $100 \mathrm{~h}$. After that, suspended solution was separated by the filtration for $2 \mathrm{~h}$. These crystals were evaluated by X-ray diffraction and Emission spectrum. The composition of the obtained crystals is written as $\times$ (molar ratio of guest-organic molecule $\mathrm{G} /$ host-inorganic molecule $\mathrm{H}$ ).

\section{Results and Discussion}

1. Structure and luminescence properties of crystals

PXRD pattern of these crystals fabricated from different molar ratio solutions were demonstrated in Figure 1. From here, the crystals generated from the solution of a low molar ratio had the crystal frame of the potassium sulfate. On the other hand, the crystals generated from the solution of a high molar ratio had the crystal frame of ABSA.

Figure 2 showed the emission spectra of crystals fabricated from different molar ratio solution. The measurement conditions were $254 \mathrm{~nm}$ excitation and room temperature. As for the $\mathrm{K}_{2} \mathrm{SO}_{4}$ host crystals (molar ratio 0.01 , and 0.05), it is understood that a new luminescene peak exists in the area of $370 \mathrm{~nm}$ and $450 \mathrm{~nm}$ that doesn't exist in former crystal. In contrast, the new luminescence peak was not able to be confirmed to ABSA host crystal (molar ratio 0.3).

From phosphorescence measurement, it has been understood that luminescence appears to $450 \mathrm{~nm}$ was a phophrescence. From both figures, the emission characteristics of the organic compound-containing inorganic crystals seem to be expressed when organic molecules located in inorganic matrices. It is thought that the appearance of the new phosphorescence characteristic in this $\mathrm{K}_{2} \mathrm{SO}_{4}$ as an organic compound-containing inorganic crystal originates in the intermolecular interaction between an organic molecule and inorganic host matrix. These crystals efficiently reduce the non-radiative decay of emission center by an inorganic-organic interaction [11] [12]. Figure 3 showed the phosphorescence spectrum of ABSA and crystal measured at different temperature. From this figure, crystal luminous intensity measured at $77 \mathrm{~K}$ is greater than the emission intensity of the crystal measured at $298 \mathrm{~K}$. By contrast, there were significant differences in ABSA crystal. This shows that the non-radiative decay process of originating in the molecular motion in an organic compound-containing inorganic crystal has been reduced, and is thought that the molecular interaction formed between host and guest.

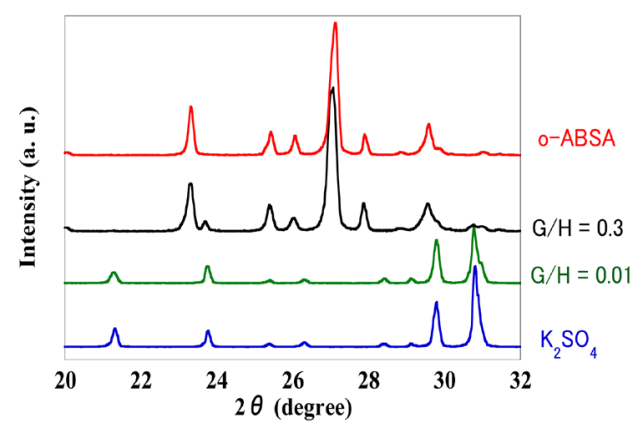

Figure 1. PXRD pattern of crystals fabricated from different molar ratio water solutions. 


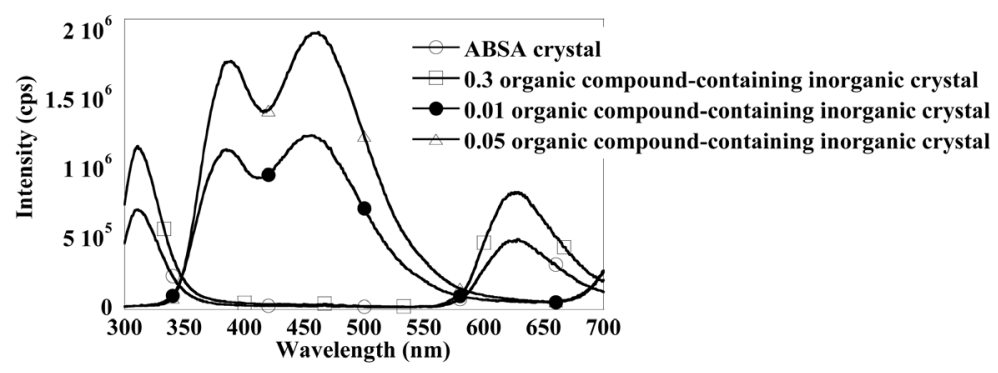

Figure 2. Emission spectra of crystals obtained and ABSA crystal by $254 \mathrm{~nm}$ excitation (molar ratio of guest molecule/host molecule).
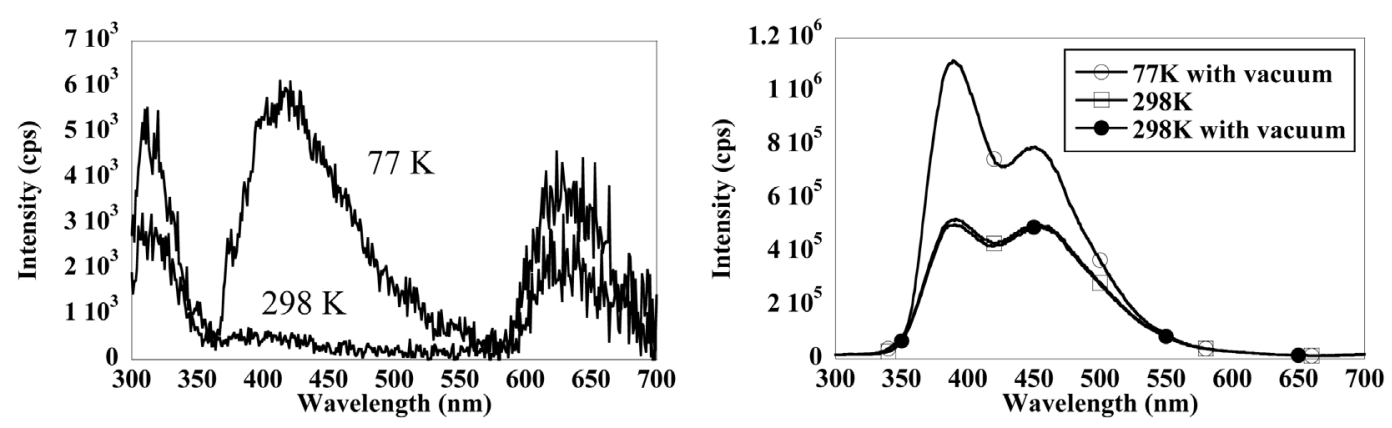

Figure 3. Phosphorescence spectra of crystals measured in different conditions (77 K and $298 \mathrm{~K}$ ) with $254 \mathrm{~nm}$ excitation by delay time $50 \mathrm{~m} \mathrm{sec}$.

2. Relationship between quantum yield and crystal composition.

To optimize the crystal composition of organic compound-containing inorganic crystals, the quantum yields were measured and relationship between quantum yield and crystal composition were demonstrated in Figure 4. It can be seen that, maximum quantum yield was 32.1\% (observed at crystal composition $=7.51 \times 10^{-3}$ ), and it gradually decreased as the distance from crystal composition $=7.51 \times 10^{-3}$ both low and high area. Decrement of quantum yield in the low crystal composition area was caused because the density of the taken organic molecule in organic compound-containing inorganic crystals were low, and an appropriate organic compound-containing inorganic structure was not able to be formed. On the other hand, the decrement of quantum yield in high crystal composition area was caused by triplet-triplet annihilation [13]. So, it indicated that crystal composition had considerable effect on quantum yields. Therefore, to fabricate an organic compound-containing inorganic crystal of high quantum yield, it was shown to have to control the crystal composition highly.

3. Emission wavelength control by changing structure of organic molecules inserted in same host structure.

It is well known that $\pi$-conjugate length of organic molecules significantly affects emission wavelength. So, we try to control the emission wavelength by regulate the $\pi$-conjugate length of organic molecules incorporated in inorganic host crystals. We fabricated and evaluated the crystal that used ABSA and NS as a guest molecule, respectively. Two kinds of guest molecules that had been used this time were thought that a basic frame was the difference (benzene and the naphthalene), and was the best for the evaluation of the control of wavelength by the change in the structure. Figure 5 shows the emission spectra of organic compound-containing inorganic crystals fabricated by changing organic molecules. It shows that ABSA compound-containing inorganic crystal has a fluorescence and phosphorescence band about $385 \mathrm{~nm}$ and $455 \mathrm{~nm}$, respectively. On the other hand, NS compound-containing inorganic crystal has a fluorescence and phosphorescence band about $405 \mathrm{~nm}$ and $510 \mathrm{~nm}$, respectively. As a result, it was shown to be able to control the luminescence wavelength of an organic compound-containing inorganic crystal by controlling the structure. However, a further research is necessary to use this organic compound-containing inorganic crystal as an illuminant for the single luminescence layer because it is difficult for achieving the red color emission from the viewpoint of the water solubility of the organic molecule in similar structure.

4. Influence of the host structure to the emission characteristic of organic compound-containing inorganic crystals. 


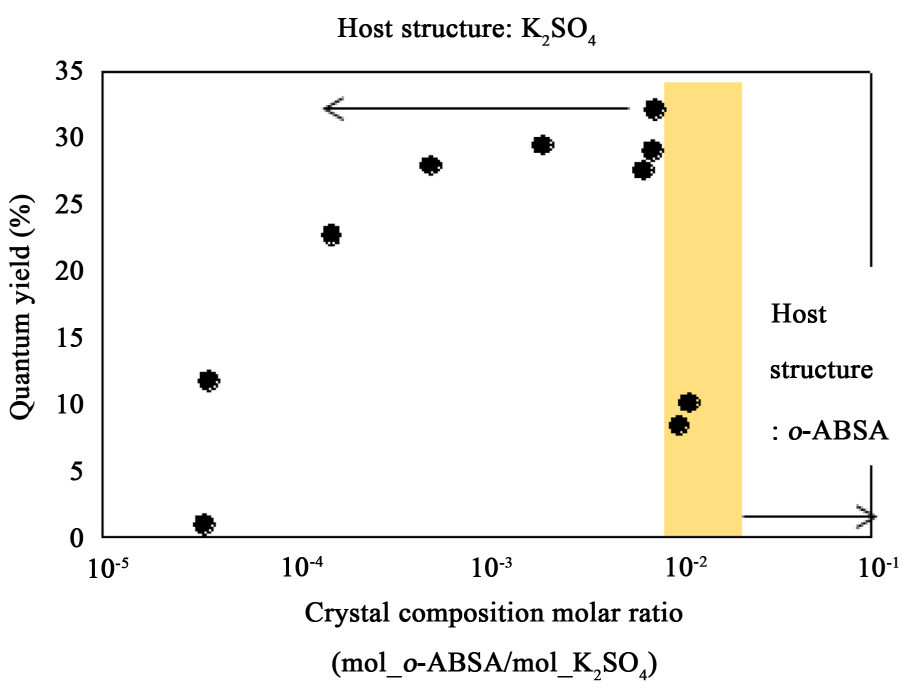

Figure 4. Relationship between quantum yield and crystal composition (molar ratio of guest molecule/host molecule) on crystals obtained.

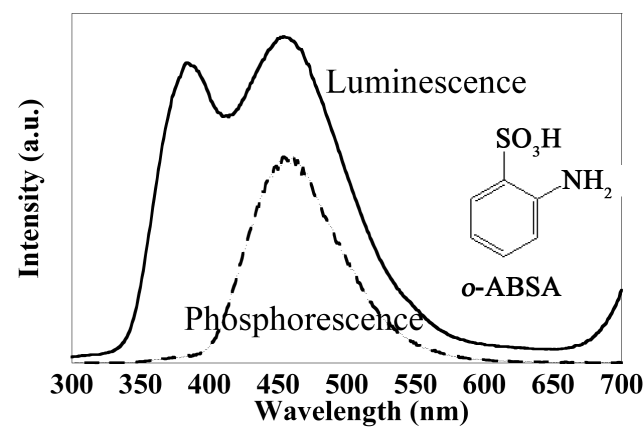

(a)

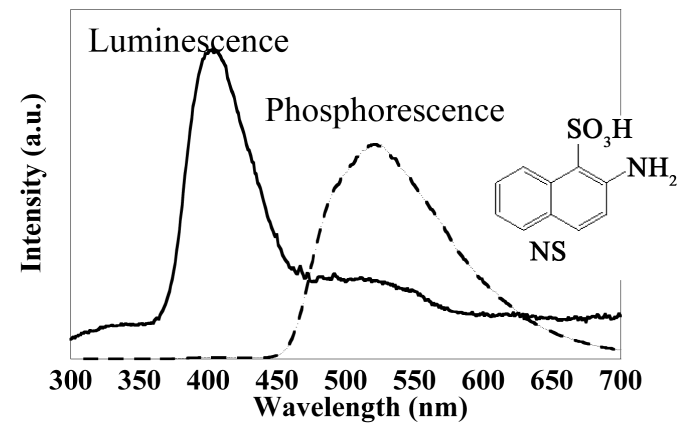

(b)

Figure 5. Normalized luminescence and phosphorescence spectra of organic compound- containing inorganic crystals crystallized from different organic molecules at $254 \mathrm{~nm}$ excitation (Phosphorescence spectra were measured at $50 \mathrm{~m} \mathrm{sec}$ after excitation.). (a) ABSA as a guest, and crystal composition is $1.99 \times 10^{-3}$; (b) NS as a guest, and crystal composition is $3.61 \times 10^{-5}$.

To investigate the effect of the crystallographic structure of host matrices for emission properties of the organic compound-containing inorganic crystals, we fabricated and compared the organic compound-containing inorganic crystals by using Potassium sulfate and Rubidium sulfate as a host. 3D Emission spectra of organic compound-containing inorganic crystals fabricated by changing host matrices were shown in Figure 6. From this figure, it shows that $\mathrm{K}_{2} \mathrm{SO}_{4}$ host organic compound-containing inorganic crystal has two emission peaks located at $385 \mathrm{~nm}$ and $455 \mathrm{~nm}$. From phosphorescence measurement, emission located at $385 \mathrm{~nm}$ and $455 \mathrm{~nm}$ were identified as fluorescence and phosphorescence, respectively. On the other hand, $\mathrm{Rb}_{2} \mathrm{SO}_{4}$ host organic compound-containing inorganic crystal have only phosphorescence peak located at $450 \mathrm{~nm}$. In addition, compared with potassium sulfate organic compound-containing inorganic crystal, the phosphorescent intensity of the rubidium sulfate organic compound-containing inorganic crystal was very strong. $\mathrm{Rb}_{2} \mathrm{SO}_{4}$ used as a host, achieved a high quantum yield around $60 \%$ by optimizing the crystal composition. This results indicate the potential to create a more efficient emitter for $\mathrm{Rb}_{2} \mathrm{SO}_{4}$ as a host

\section{Conclusion}

The luminescent functional crystal was produced by taking the organic molecules in the inorganic crystal matrices. The organic compound-containing inorganic crystals had a phosphorescent property in room temperature. It is suggested that the phosphorescence characteristic appears since the host matrix effectively controls the 


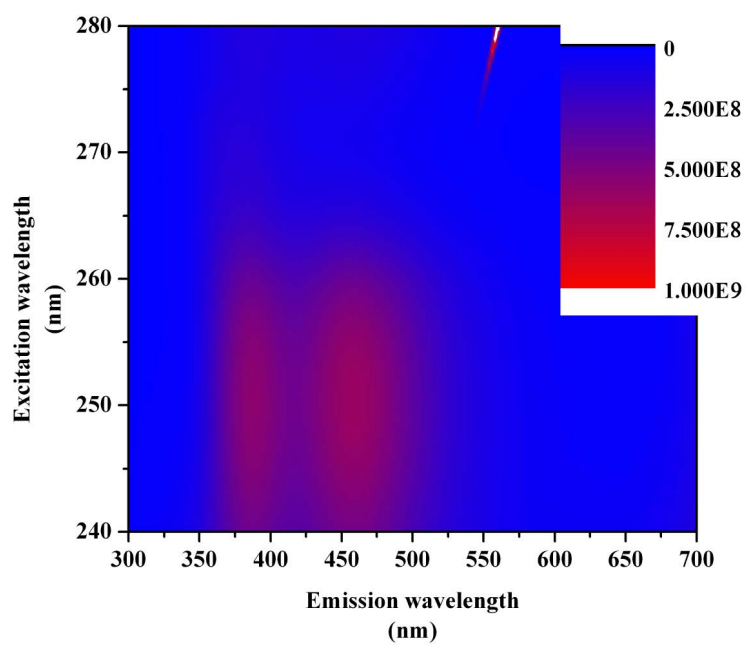

(a)

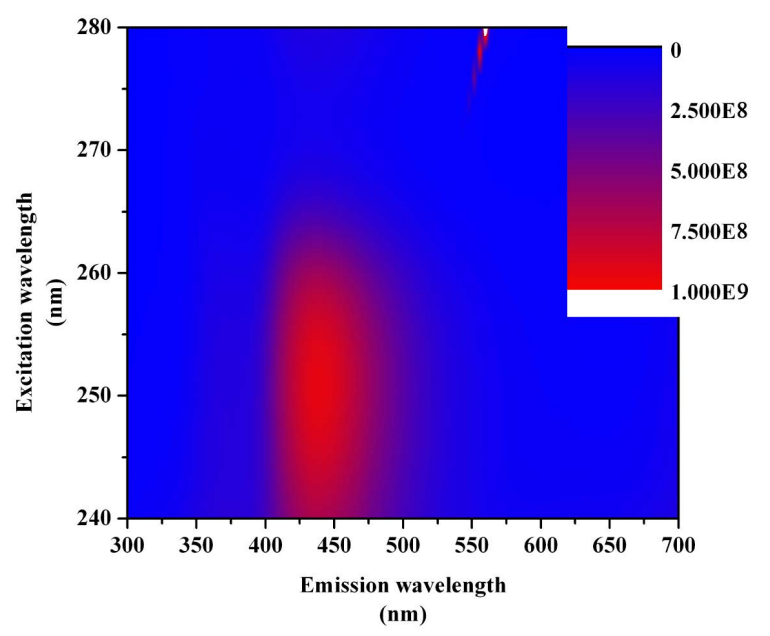

(b)

Figure 6. 3D spectra of organic compound-containing inorganic crystals crystallized by changing host molecules. (a) $\mathrm{K}_{2} \mathrm{SO}_{4}$ as a host; (b) $\mathrm{Rb}_{2} \mathrm{SO}_{4}$ as a host.

thermal motion of the guest organic molecules. The phosphorescence wavelength was able to be controlled by controlling the molecular configuration of the organic molecules in the same host frame. Therefore, there is a possibility that an organic compound-containing inorganic crystal can be applied to the illuminant.

\section{References}

[1] D’Andrade, B.W. and Forrest, S.R. (2004) White Organic Light-Emitting Devices for Solid-State Lighting. Advanced Materials, 16, 1585-1595. http://dx.doi.org/10.1002/adma.200400684

[2] Sun, R.Y., Giebink, N.C., Kanno, H., Ma, B.W., Thompson, M.E. and Forrest, S.R. (2006) Management of Singlet and Triplet Excitons for Efficient White Organic Light-Emitting Devices. Nature, 440, 908-912. http://dx.doi.org/10.1038/nature04645

[3] Kanno, H., Holmes, R.L., Sun, R.Y., Kena-Cohen, S. and Forrest, S.R. (2006) White Stacked Electrophosphorescent Organic Light-Emitting Devices Employing $\mathrm{MoO}_{3}$ as a Charge-Generation Layer. Advanced Materials, 18, $339-342$. http://dx.doi.org/10.1002/adma.200501915

[4] Su, S.-J., Gonmori, E., Sasabe, H. and Kido, J. (2008) Highly Efficient Organic Blue-and White-Light-Emitting Devices Having a Carrier- and Exciton-Confining Structure for Reduced Efficiency Roll-Off. Advanced Materials, 20, 4189-4194.

[5] Wang, Q., Ding, J.Q., Ma, D.G., Cheng, Y.X., Wang, L.X. and Wang, F.S. (2009) Manipulating Charges and Excitons within a Single-Host System to Accomplish Efficiency/CRI/Color-Stability Trade-Off for High-Performance OWLEDs. Advanced Materials, 21, 2397-2401. http://dx.doi.org/10.1002/adma.200803312

[6] Reineke, S., Lindner, F., Schwartz, G., Seidler, N., Walzer, K., Lüssem, B. and Leo, K. (2009) White Organic LightEmitting Diodes with Fluorescent Tube Efficiency. Nature, 459, 234-238.

[7] Wang, Q., Ding, J.Q., Ma, D.G., Cheng, Y.X., Wang, L.X., Jing, X.B. and Wang, F.S. (2009) Harvesting Excitons via Two Parallel Channels for Efficient White Organic LEDs with Nearly 100\% Internal Quantum Efficiency: Fabrication and Emission-Mechanism Analysis. Advanced Functional Materials, 19, 84-95. http://dx.doi.org/10.1002/adfm.200800918

[8] Yang, C.-H., Cheng, Y.-M., Chi, Y., Hsu, C.-J., Fang, F.-C., Wong, K.-T., Chou, P.-T., Chang, C.-H., Tsai, M.-H. and Wu, C.-C. (2007) Blue-Emitting Heteroleptic Iridium (III) Complexes Suitable for High-Efficiency Phosphorescent OLEDs. Angewandte Chemie International Edition, 46, 2418-2421. http://dx.doi.org/10.1002/anie.200604733

[9] Peng, T., Yang, Y., Bi, H., Lin, Y., Hou, Z.M. and Wang, Y. (2011) Highly Efficient White Organic Electroluminescence Device Based on a Phosphorescent Orange Material Doped in a Blue Host Emitter. Journal of Materials Chemistry, 21, 3551-3553. http://dx.doi.org/10.1039/c0jm03645e

[10] Gurney, R.W., Mitchell, C.A., Ham, S., Bastin, L.D. and Kahr, B. (2000) Salting Benzenes. Journal of Physical Chemistry B, 104, 878-892. http://dx.doi.org/10.1021/jp992424p

[11] Carter, D.J., Ogden, M.I. and Rohl, A.L. (2007) Mechanisms of Dye Incorporation into Potassium Sulfate: Computa- 
tional and Experimental Studies. Journal of Physical Chemistry C, 111, 9283-9289. http://dx.doi.org/10.1021/jp071177j

[12] Bastin, L.D. and Kahr, B. (2000) Engineering Oriented Gases: The Mechanism of Dyeing Potassium Sulfate. Tetrahedron, 56, 6633-6643. http://dx.doi.org/10.1016/S0040-4020(00)00464-6

[13] Baldo, M.A., Thompson, M.E. and Forrest, S.R. (2000) High-Efficiency Fluorescent Organic Light-Emitting Devices Using a Phosphorescent Sensitizer. Nature, 403, 750-753. http://dx.doi.org/10.1038/35001541 